\title{
Initial size structure of natural phytoplankton communities determines the response to Daphnia diel vertical migration
}

\author{
Florian HAUPT,,${ }^{1,4 *}$ Maria STOCKENREITER, ${ }^{1,4}$ Maarten BOERSMA, ${ }^{2}$ and Herwig STIBOR ${ }^{3,4}$ \\ ${ }^{1}$ Syke - Finnish Environment Institute, Marine Research Centre, Mechelininkatu 34a, 00251 Helsinki, Finland; ${ }^{2}$ Alfred-Wegener- \\ Institut für Polar- und Meeresforschung, Biologische Anstalt Helgoland, Postfach 180, 27483 Helgoland, Germany; ${ }^{3}$ Institut Univer- \\ sitaire Européen de la Mer, Technopôle Brest-Iroise, Place Nicolas Copernic, 29280 Plouzané, France; ${ }^{4}$ Present address: Ludwig- \\ Maximilians-Universität München, Department Biologie II, Grosshaderner Str. 2, 82152 Planegg-Martinsried, Germany \\ *Corresponding author: haupt@bio.lmu.de
}

\begin{abstract}
Diel vertical migration (DVM) is a common behavior of many pelagic herbivorous zooplankton species in response to predation pressure. It is characterized by a twice daily habitat shift of the zooplankton species: staying in the epilimnion only during night time and migrating down in the crack of dawn in deeper water layers, staying there during the day time. This causes a discontinuous grazing regime and previous studies have shown that the direction and strength of phytoplankton community responses to zooplankton DVM most probably depends on the size of phytoplankton species. To examine the influence of zooplankton DVM on different sized phytoplankton communities, we designed an experiment where we manipulated the size distribution of a natural phytoplankton community a priori in field mesocosms. We investigated the influence of DVM of the cladoceran Daphnia hyalina on two different phytoplankton communities, by the use of deep $(10 \mathrm{~m})$ field enclosures. Epilimnetic lake water, containing a summer phytoplankton community, was filtered with two different mesh sizes (11 $\mu \mathrm{m}$ and $64 \mu \mathrm{m})$. The 11 um phytoplankton community ("small") contained mainly small algal species, while the 64 m community ("large") had a wider range of phytoplankton sizes. To simulate zooplankton DVM, D. hyalina were placed in mesh cages that were lowered or raised ("migration") as dictated by the study design; a "no migration" (representing absence of DVM) treatment was also tested. Phytoplankton abundance was measured using chlorophyll-a and biovolume; size distribution of the algae and nutrient availability was also determined in each treatment. The results indicated that DVM had contrasting effects on the two evaluated phytoplankton communities. Comparison of "migration" and "no migration" zooplankton treatments showed that nutrient availability and total phytoplankton biovolume was higher in (1) "no migration" treatments with phytoplankton communities comprising mainly small algae and (2) "migration" treatments with phytoplankton communities of a broader size spectrum of algae. Hence our study showed two different mechanisms of how zooplankton DVM may influence the phytoplankton community dynamics. Nutrient cycling was an important factor in phytoplankton communities of mainly small algae, whereas the refuge effect was the main driver of phytoplankton dynamics in phytoplankton communities of a large size spectrum of algae
\end{abstract}

Key words: behavior, algae, trait mediated interactions, nutrients, refuge effect.

Received: September 2011. Accepted: November 2011.

\section{INTRODUCTION}

Natural primary producer communities typically comprise many species of various taxonomic levels with vastly different body sizes (Gaston, and Lawton 1988). Body size is an important feature in many food web models because of its importance in numerous ecological interactions, including inter-species competition and prey selection by predators (Cohen et al. 1993; Williams, and Martinez 2000). The impact of size structure on ecological interactions in pelagic ecosystems may be substantial. For example, predatorprey relationships are almost exclusively based on larger organism eating smaller organisms, with non-lethal herbivory being practically absent in these systems.

The PEG model (Sommer et al. 1986) of annual plankton succession in lakes demonstrates the significant relationship between size structure and pelagic ecosystem dynamics. Interactions are linked to the size structure and composition of the plankton community, which are subject to substantial seasonal fluctuations. Seasonal changes are further influenced by, and linked to, other abiotic and biotic factors, such as temperature gradients, nutrient availability, intra- and interspecific competition, and predation. The greatest annual community shift in temperate pelagic freshwater ecosystems, described by the PEG model, generally occurs at the end of the "clear water" phase in late spring/early summer. At this time, the community of small algae transforms into the summer community of large, grazing-resistant algae, thus influencing food availability for zooplankton.

The transition between spring and summer phytoplankton communities is often characterized by a high abundance of juvenile fish, which start to populate the pelagic zone and prey on the zooplankton. Strong predation pressure 
triggers avoidance behavior in many zooplankton species (such as Daphnia), resulting in "diel vertical migration" (DVM) behavior. DVM is one of the most important escape responses exhibited by aquatic herbivores (Hays 2003) and it has been shown, that DVM can be a feature in a lake nearly throughout the whole year (Huber et al. 2011). Zooplankton species performing DVM spend the night primarily in upper water layers, migrating down the water column at dawn to spend the day in deeper, darker and, colder waters (Lampert 1989). Because fish feed visually, behavioral studies have clearly established predator avoidance as the primary ultimate driver for DVM (Zaret, and Suffern 1976). The immediate triggers initiating vertical migration behavior by zooplankton are the changes in light intensity around dawn and dusk (Ringelberg 1991), while the presence of a chemical substance (kairomone) that is released by predatory fish affects the motivation of zooplankton to respond to these triggers (Loose et al. 1993).

While many studies have investigated the effects of DVM on the population dynamics of the zooplankters (Lampert et al. 1988; Loose, and Dawidowicz 1994; Reichwaldt et al. 2005), little research has been directed toward the potential consequences of DVM for phyto-plankton dynamics, possibly because of the difficulties in inducing and regulating migration behaviour in controlled experiments. Conceivably are different mechanisms through which DVM of zooplankton can influence epilimnetic phytoplankton communities. Perhaps the most substantial impact is reduced grazing pressure, due to lower zooplankton densities. For example, migrating zooplankton populations encounter lower temperatures in the hypolimnion than in the epilimnion. These lower temperatures lead to slower somatic growth, which may ultimately lead to lower population growth (Loose, and Dawidowicz 1994). The lower density of migrating compared to non-migrating zooplankton populations is certainly only the case if one leaves out predation as a potential mortality factor, because if predation was present, a non-migrating population would also have lower growth due to this predation (Stich, and Lampert 1984).

The second possible mechanism affecting epilimnetic phytoplankton communities is that zooplankton migration leads to the daytime period being generally free of grazing, which results in intermittent grazing pressure on the phytoplankton community in the epilimnion. Because both of these mechanisms may lead to reduced grazing pressure on phytoplankton, it is assumed that both may significantly enhance phytoplankton biomass (Lampert et al. 1986; Reichwaldt et al. 2004). Results of recent studies also suggest a third mechanism, whereby the migration of zooplankton may have a significant effect on epilimnetic nutrient supplies due to a change in nutrient recycling. Specifically, Lampert, and Grey (2003) showed that DVM by Daphnia may result in the upward transport of nitro- gen, while Haupt et al. (2010) showed an enrichment of upper water layers with phosphorus by Daphnia DVM.

Theoretical models have been developed using available data to estimate the impacts of zooplankton DVM on phytoplankton communities, in which discontinuous zooplankton grazing under DVM is indicated to enhance phytoplankton biomass by fostering small and fast growing algal species (Lampert 1987). A model developed by Petzoldt et al. (2009) showed that reduced zooplankton grazing and changed nutrient recycling under DVM are important mechanisms influencing plankton dynamics. The few experiments that have been conducted to investigate the effects of zooplankton DVM on pelagic ecosystems show that it may affect phytoplankton abundance, species composition, and diversity (Reichwaldt, and Stibor 2005; Haupt et al. 2009).

One emerging hypothesis from the post hoc analyses of experimental studies (Reichwaldt, and Stibor 2005; Reichwaldt et al. 2004; Haupt et al. 2009), is that the effects of zooplankton DVM on phytoplankton communities are species-specific, probably depending on the size of particular phytoplankton taxa and the acceptable food-size range of zooplankton. Because small phytoplankton species normally have higher growth rates than larger species (Reynolds, and Irish 1997), they may use spatial and temporal refuges created by zooplankton DVM more efficiently. Hence, small fast growing edible algae may benefit more from DVM than larger slow-growing taxa within the community. Conversely, communities that consist mainly of large inedible algae may benefit from relatively constant uninterrupted grazing by non-migrating zooplankton on the few edible taxa. Additionally, zooplankton release nutrients through sloppy feeding and excretion, which further increases the abundance of inedible algae within the community.

Hence, we hypothesize that differences in the size structure of phytoplankton communities will affect the response of phytoplankton communities to zooplankton DVM. If correct, experimental manipulation of the size distribution of a phytoplankton community should alter its response to zooplankton DVM. To investigate this hypothesis, we manipulated the size distribution of a natural phytoplankton community in large (7000 L) field mesocosms, representing two differently size structured phytoplankton communities (either with mainly small species or with a larger size spectrum of species). The resulting communities were exposed to migrating and non-migrating populations of Daphnia. We consider our results against theories of phytoplankton community responses to Daphnia DVM, and potential trophic web impacts.

\section{MATERIALS AND METHODS}

The study was conducted in an experimental enclosure system deployed in oligotrophic Lake Brunnensee, south- 
ern Germany $\left(47^{\circ} 59^{\prime} \mathrm{N}, 12^{\circ} 26^{\prime} \mathrm{E}\right)$, in the summer (JuneJuly) of 2007. This small (5.8 ha), deep (18.6 m), hardwater lake is strongly phosphorus-limited (total P: $12 \mathrm{ng}$ $\left.\mathrm{L}^{-1}\right)$, with a high nitrate concentration $\left(\mathrm{NO}_{3}: 5 \mathrm{mg} \mathrm{L}^{-1}\right)$ during the summer. To investigate the effects of vertically migrating zooplankton on two differently size structured phytoplankton communities, we moved Daphnia populations up and down the water column using cages. To create the two different phytoplankton communities, epilimnetic lake water containing a summer phytoplankton community was filtered using meshes (Sefar Petex, Sefar AG, Switzerland) with either a $11 \mu \mathrm{m}$ or $64 \mu \mathrm{m}$ mesh size.

The submersible cages used in this study had already been successfully applied in earlier experiments (Reichwaldt, and Stibor 2005; Haupt et al. 2009). Although predation is considered to be one of the most important causes of zooplankton DVM (Zaret, and Suffern 1976), attempts to establish a predatory dynamic by fish stocking have proven very difficult, primarily due to potential indirect effects on phytoplankton caused by nutrients excreted by enclosed fish (Schindler 1992; Vanni, and Layne 1997; Attayde, and Hansson 1999). In practice, it is also not possible to induce zooplankton DVM behavior using kairomones because too little is known about the structure and dose-effect relationship of these chemical signals.

\section{Experimental design}

Twenty four cylindrical enclosures (transparent Trikoron bags, Rheinische Kunststoffwerke Worms, Germany) were suspended vertically from a raft to a depth of $10 \mathrm{~m}$. Each $0.9 \mathrm{~m}$ diameter enclosure was heat-sealed at the bottom and open to the atmosphere. In the enclosures, we mimicked an unmixed, $6 \mathrm{~m}$ deep hypolimnion and a wellmixed, $4 \mathrm{~m}$ deep epilimnion. The latter was produced by intermittently bubbling compressed air ( $3 \mathrm{~min}$ on, $40 \mathrm{~min}$ off) through PVC-tubes at a depth of $4 \mathrm{~m}$. To prevent a vertical temperature gradient in the enclosures, all were surrounded by a $15 \mathrm{~m}$ deep, transparent silage film $(0.2$ $\mathrm{mm}$ ), which acted as a homogenous, tempered water bath. Uniform mixing in the water bath was achieved by the intermittent injection of compressed air (5 min on, $20 \mathrm{~min}$ off) at a depth of $12 \mathrm{~m}$.

Homogenous temperature along the vertical gradient was necessary to achieve similar growth in migrating and non-migrating Daphnia populations. Reichwaldt, and Stibor (2005) showed a fluctuating temperature regime had a significantly negative impact on the population growth and hence abundance of migrating Daphnia. In this study, we aimed to investigate the refuge effect of Daphnia DVM on phytoplankton communities of different size structures, and the consequences of DVM on nutrient dynamics in such communities. Therefore we used a modification of the experimental setup of Reichwaldt, and
Stibor (2005) to separate refuge effects from temperature effects. This method, constructs a well-mixed water bath around all enclosures, allowing the refuge effect of zooplankton DVM to be examined under field conditions without significant temperature differences between upper and deeper water layers.

Twelve enclosures were filled with $64 \mu \mathrm{m}$ filtered epilimnetic water, and another 12 were filled with $11 \mu \mathrm{m}$ filtered epilimnetic water. The $11 \mu \mathrm{m}$ filtered communities consisted mainly of small phytoplankton species, whereas the $64 \mu \mathrm{m}$ filtered communities consisted of a variety from small to large phytoplankton species (Fig. 1). From this point onwards, we therefore refer to the 11 $\mu \mathrm{m}$ filtered communities as "small" communities and the $64 \mu \mathrm{m}$-filtered communities as "large" communities. For a detailed description of the natural summer phytoplankton community in Lake Brunnensee see Haupt et al. (2009). Filtration and the filling of the enclosures began on 19 June 2007 , which took approximately $48 \mathrm{~h}$. The enclosures were filled haphazardly with either "small" or "large" phytoplankton. After filling the enclosures, the "small" community enclosures were enriched with $10 \mu \mathrm{g}$ $\mathrm{KH}_{2} \mathrm{PO}_{4} \mathrm{~L}^{-1}$ to attain similar particulate phosphorus concentrations in all treatments, due to the particulate material having been removed from these enclosures.

Daphnia were placed in a cylindrical mesh cage (224 $\mu \mathrm{m}$ mesh aperture, diameter $0.7 \mathrm{~m}$, length $3.5 \mathrm{~m}$; Sefar Petex, Sefar AG, Switzerland) inside each enclosure. This mesh aperture ensured that all Daphnia were retained within the cages, while allowing the free exchange of algal cells. Each cage had a mesh cap that could be resealed to allow sampling. The volume of the cages was approximately $50 \%$ of the epilimnion. To simulate DVM, cages were moved up and down the water column within the enclosures in a diurnal rhythm.

For the "migration" treatment group, cages containing Daphnia were kept in the epilimnion (top of cage: $0.25 \mathrm{~m}$ depth) at night (20:00-08:00 h), and then lowered into the hypolimnion (top of cage: $5.5 \mathrm{~m}$ depth) during the day (08:00 $\mathrm{h}$ to $20: 00 \mathrm{~h})$. Cages were manually moved as slowly as possible (maximum speed: $0.05 \mathrm{~m} \mathrm{~s} 1$ ). For the "no migration" treatment group, the cages containing Daphnia were kept permanently in the epilimnion. Although previous studies detected no plankton or nutrient dynamic effects from the movement of the cages (Reichwaldt, and Stibor 2005; Haupt et al. 2009), we again evaluated this possibility by installing enclosures with migrating empty (no Daphnia) cages, and enclosures with non-migrating empty cages. Therefore, the twelve "small" enclosures and the twelve "large" enclosures included three Daphnia "migration" treatments, three Daphnia "no migration" treatments, three migrating empty cages, and three non-migrating empty cages.

We used a clone of Daphnia hyalina originating from 
Lake Brunnensee, which is known to perform DVM in this lake (H. Stibor, unpublished data), to stock the cages. Prior to the experiment, Daphnia were reared in $30 \mathrm{~L}$ buckets, with an artificial culture medium in an environmental chamber at a constant temperature of $20^{\circ} \mathrm{C}$. They were fed Scenedesmus obliquus ( $\left.>1 \mathrm{mg} \mathrm{C} \mathrm{L}^{-1}\right)$ every other day, and $50 \%$ of their medium was renewed every $5 \mathrm{~d}$. Two days before the beginning of the experiment, all Daphnia were transferred to $30 \mu \mathrm{m}$ filtered, epilimnetic lake water. At the beginning of the experiment, Daphnia were released into the Daphnia "migration" and Daphnia "no migration" treatment cages at a starting density of five individuals $\mathrm{L}^{-1}$ within the epilimnion, which is a density that is typical for this species in Lake Brunnensee (H. Stibor, unpublished data).

The experiment began with the stocking of Daphnia on 25 June 2007 (day 0), $5 \mathrm{~d}$ after filling the enclosures, to compensate phytoplankton growth from the losses caused by the $11 \mu \mathrm{m}$ filtration in the "small" community treatments. The experiment lasted for four weeks until 24 July 2007 (day 29). This has proven to be an ecologically rational time span for enclosure experiments, because it is long enough to show strong effects on the monitored parameters, but short enough to prevent the occurrence of artificial effects in the enclosures, such as extensive wall growth (Reichwaldt, and Stibor 2005; Haupt et al. 2009).

\section{Sampling program}

Water temperature was measured weekly at $1 \mathrm{~m}$ vertical intervals using a WTW model Lf 191 meter with LT1/T probe (Wissenschaftlich-Technische Werkstätten, Germany). Vertical profiles of photosynthetically-active radiation (PAR) were measured once in all enclosures on day 14, using a LI-139SA spherical quantum sensor (LiCor, USA). In the "no migration" treatment groups, where cages remained in the epilimnion throughout the day, light intensity was measured with the cages in place, to account for possible shading effects. In both "migration" and "no migration" conditions, PAR was measured stepwise at $1 \mathrm{~m}$ intervals from the surface to a depth of 7 $\mathrm{m}$, and was used to calculate the depthaveraged light attenuation coefficient (Diehl et al. 2002) for each enclosure. A $t$-test revealed no significant differences in PAR between the "migration" and "no migration" treatments in the "small" and "large" enclosures ("small" community: $\mathrm{t}_{(10)}=0.02 ; p=0.98$; "large" community: $\mathrm{t}_{(10)}=0.39$; $p=0.70$ ). This data validated that "migration" and "no migration" treatments were not impacted by different shading regimes in either phytoplankton community.

At the start (day 1) and end (day 29) of the experiment, water samples were collected from outside the cages in each enclosure at a depth of $0.5 \mathrm{~m}$ (epilimnion) and $7 \mathrm{~m}$ (hypolimnion) using a hand pump. All samples were collected before the "migration" treatment cages were low- ered to the hypolimnion. The samples were filtered through a $250 \mu \mathrm{m}$ mesh screen, and immediately analyzed for biological and chemical parameters. Concentrations of soluble reactive phosphorus (SRP) and silicate $\left(\mathrm{SiO}_{2}\right)$ were measured following standard methods (Wetzel, and Likens 1991). Nitrate concentration was measured by ion chromatography (Model 300, Dionex Corporation, USA). Chlorophyll- $a$ concentrations were determined fluorometrically (TD 700, Turner Design, USA).

To analyze the total biovolume and size spectrum of the two phytoplankton communities, we immediately preserved subsamples of the collected water samples with acid Lugol's iodine. These samples were measured with a particle counter (Casy 1, Schärfe Systems, Germany). Plankton particles were sorted according to equivalent spherical diameter (ESD). The ESD was then used to determine 22 size classes. For each size class, we pooled the biovolume of all particles around $\pm 0.5 \mu \mathrm{m}$ of each respective ESD size class. Hence the smallest size class was 4 $\mu \mathrm{m}$ ESD, including the biovolume of all particles between $3.5 \mu \mathrm{m}$ and $4.5 \mu \mathrm{m}$ ESD, while the largest size class was $25 \mu \mathrm{m}$ ESD, including the biovolume of all particles between $24.5 \mu \mathrm{m}$ and $25.5 \mu \mathrm{m}$ ESD.

At the end of the experiment (day 29), zooplankton samples from all cages were collected to test the potential effects of the migrating cage on Daphnia growth. To accomplish this, in the morning before the migrating cages were lowered, all cages were opened at the top and mixed with a Secchi disc (the Secchi disc was lowered and brought up two times in each cage) to uniformly distribute the zooplankton. A vertical net haul from the bottom to the top inside the cage (net diameter: $0.25 \mathrm{~m}$; mesh size: $150 \mu \mathrm{m})$ was then taken. This sampling method allowed direct comparisons between enclosures, although it probably under-sampled actual Daphnia densities inside the cages, because Daphnia that remain near to the cage bottom are not effectively caught (Haupt et al. 2009). The samples were preserved in $4 \%$ sucrose-formaldehyde solution (Haney, and HalL ${ }^{-1} 973$ ), and all zooplankton individuals were counted under a dissecting microscope.

\section{Data processing}

In this study we were interested in the mechanisms of how discontinuous grazing caused by zooplankton DVM may influence phytoplankton communities. Therefore, we used the data from the end of the experiment (day 29), in which we expected to observe the largest effects on the monitored parameters, for the analysis of the algal communities. Because all available theoretical models investigating zooplankton DVM are focused on the effects of DVM on epilimnetic algal communities, we primarily report data from this layer.

The total biovolume and biovolume of each size class of the phytoplankton communities were used to calculate 
the percentage biovolume of each size class at the start (day 1) and the end of the experiment (day 29). We used this data to predict the development of phytoplankton biomass $r_{(i)}$ of each size class during the experiment from the logarithms of the biovolume percentage. We used for the calculations a modified version of the population growth rate (PGR) formula:

$$
r_{(i)}=\left(\ln B V P(i)_{\text {end }} \ln B V P(i)_{\text {start }}\right)
$$

where $B V P(i)_{\text {end }}$ is the biovolume percentage in size class $i$ at the end of the experiment, and $B V P(i)_{\text {start }}$ is the biovolume percentage in size class $i$ at the start of the experiment. We analyzed the biomass development $r$ of the phytoplankton size classes in "migration" and "no migration" treatments by using standard regression models. Lack of fit tests were used to determine the validity of linear models, and ANCOVA methods were used to compare the slope and intercepts of linear regressions.

Cage effects were analyzed using $t$-tests to compare migrating and non-migrating empty cage data. Two-way analysis of variance (ANOVA) (with phytoplankton community type and Daphnia migration treatment as fixed factors) was used to compare soluble reactive phosphorus concentrations, chlorophyll- $a$ and total phytoplankton biovolume between Daphnia "migration" and Daphnia "no migration" treatments. If a significant interaction between fixed factors was indicated, we performed post hoc tests using all pair wise multiple comparison procedures (Holm-Sidak method). Data are mainly presented as mean \pm one standard error of the mean. Where appropriate to meet statistical assumptions (Sokal, and Rohlf 1981), data were lntransformed.

\section{RESULTS}

Success of the experimental design

\section{Filtration and initial conditions}

Total phytoplankton biovolume at the start of the experiment (day 1) was $2.8 \times 10^{9} \pm 1.6 \times 10^{8} \mu \mathrm{m}^{3} \mathrm{~L}^{-1}$ in the "small" and $2.7 \times 10^{9} \pm 3.8 \times 10^{8} \mu \mathrm{m}^{3} \mathrm{~L}^{-1}$ in the "large" communities. $T$-tests revealed no significant differences in total biovolume between both phytoplankton communities in all 12 Daphnia treatments: $\mathrm{t}_{(22)}=0.67, p=0.51$.

Linear regressions were calculated to test for significant differences between size class biovolume percentages in the "small" and "large" phytoplankton communities at the start of the experiment of all Daphnia treatments. Biovolume percentages after filtration may be described as a linear function of size classes, with the linear regressions being significant for both communities: "small" community: $\mathrm{y}=0.57 \quad \mathrm{x}+12.08, \quad R^{2}=0.56$, $F_{1,87}=111.91, \mathrm{p}<0.001$; "large" community: $\mathrm{y}=0.29$ $\mathrm{x}+7.85, R^{2}=0.31, F_{1,85}=37.61, \mathrm{p}<0.001$ (Fig. 1). The

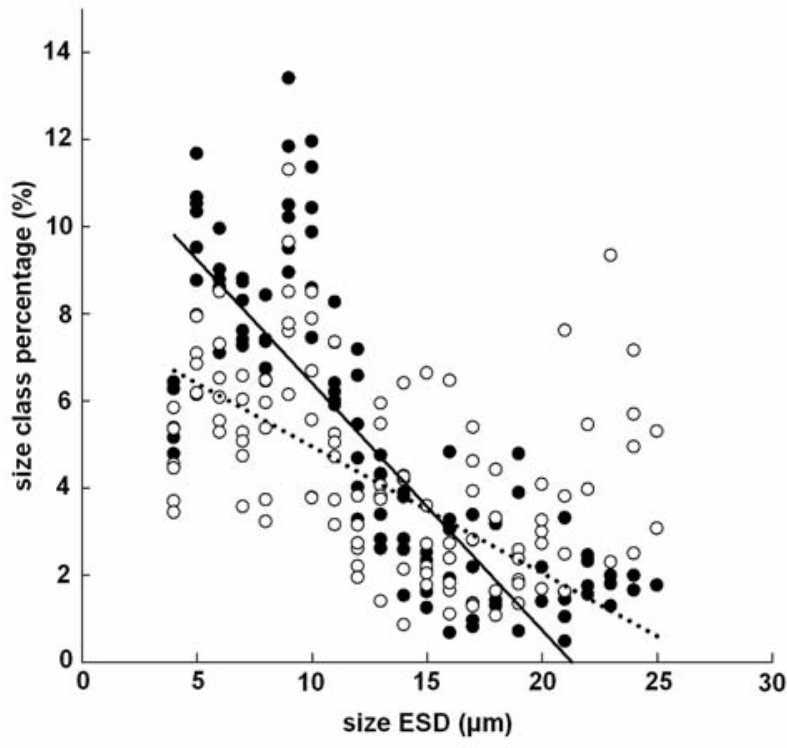

Fig. 1. Biovolume percentages of size classes in "small" (filled circles) and "large" (open circles) phytoplankton communities at the beginning of the experiment. Lines represent linear regressions: "small" community, $\mathrm{y}=0.57 \mathrm{x}+12.08, R^{2}=0.56$, $\mathrm{p}<0.001$ (solid line); "large" community, $y=0.29 x+7.85$, $R^{2}=0.31, \mathrm{p}<0.001$ (dotted line).

analysis of covariance revealed statistical differences in the biovolume percentage of size classes in both communities: slopes: $F_{1,172}=14.88, \quad \mathrm{p}<0.001$; intercepts: $F_{1,173}=15.02, \mathrm{p}<0.001$. Therefore, filtration was successful, with the "small" phytoplankton community containing more small algae size classes (size $<15 \mu \mathrm{m}$ ESD), while the "large" community contained larger algae size classes (individual size $>15 \mu \mathrm{m}$ ESD).

Initial soluble reactive phosphorus (SRP) concentrations showed no significant differences between "small" $\left(3.3 \pm 0.1 \mu \mathrm{g} \mathrm{P} \mathrm{L}^{-1}\right)$ and "large" $\left(3.1 \pm 0.1 \mu \mathrm{g} \mathrm{P} \mathrm{L}^{-1}\right)$ phytoplankton communities in all 12 Daphnia treatments on day $1: \mathrm{t}_{(10)}=1.65, p=0.13$.

\section{General conditions of the experiment}

Dissolved nitrate $\left(2.8 \mathrm{mg} \mathrm{L}^{-1} \pm 0.1\right)$ and silicate $(3.1 \mathrm{mg}$ $\mathrm{L}^{-1} \pm 0.2$ ) were measurable in high concentrations at the end of the experiment in all enclosures, and therefore not limiting during the experimental duration. Water temperature was constant in all enclosures, averaging $17.4^{\circ} \mathrm{C} \pm 0.03$ at all depths. There was virtually no vertical temperature gradient, with the difference between temperature at the surface and maximum depth $(10 \mathrm{~m})$ being just $1.5^{\circ} \mathrm{C} \pm 0.07$.

Daphnia densities inside the cages averaged $4.7 \pm 0.6$ ind $\mathrm{L}^{-1}$ based on total epilimnion volume. We found no significant differences in Daphnia densities between Daphnia "migration" and Daphnia "no migration" treat- 
ment groups for both phytoplankton communities: "small": $t_{(4)}=0.65, p=0.55$; "large": $t_{(4)}=1.07, p=0.35$. Although control treatments were not initially stocked with Daphnia, some animals were present in the water, and a Daphnia population did develop. However, Daphnia densities in the control treatments were always less than 0.1 ind $\mathrm{L}^{-1}$. Additional mesozooplanktonic organisms were, for the most part, excluded by the initial filtration, although some animals, mainly copepods, were found at densities of less than 0.1 ind $\mathrm{L}^{-1}$.

\section{Control treatments (empty cages)}

Analysis using $t$-tests revealed no significant differences between migrating and non-migrating control treatments for any of the measured parameters: "small" communities: soluble reactive phosphorus (SRP) concentration: $t_{(4)}=0.85, p=0.44$; chlorophyll- $a$ concentration: $t_{(4)}=0.02, p=0.98$; total phytoplankton bio-volume: $t_{(4)}=0.07, p=0.95$. "Large" communities: SRP concentration: $t_{(4)}=1.84, p=0.14$; chlorophyll- $a$ concentration: $t_{(4)}=1.81, p=0.14$; total phytoplankton bio-volume: $t_{(4)}=1.65, p=0.17$. To evaluate the possible effects of the cages on large diatoms, we compared the silicate $\left(\mathrm{SiO}_{2}\right)$ concentrations between migrating and non-migrating empty cages, with no significant differences being found: "small" communities: $t_{(4)}=1.74, p=0.16$; "large" communities: $t_{(4)}=0.91, p=0.41$.

Experimental results

\section{Nutrients}

Two-way ANOVA indicated a significant interaction effect of phytoplankton community type and migration behavior on soluble reactive phosphorus (SRP) $\left(F_{(1,8)}=5.67, p=0.044\right)$ (Fig. 2a). In the "small" communities post hoc analyses revealed no significant effects of migration treatments on SRP concentrations: $2.0 \pm 0.03 \mu \mathrm{g}$ $\mathrm{P} \mathrm{L}^{-1}$ in the "migration" treatments and $2.3 \pm 0.3 \mu \mathrm{g} \mathrm{P} \mathrm{L}{ }^{-1}$ in the "no migration" treatments. Post hoc analyses showed that the SRP concentrations in "large" communities were significantly higher in the "migration" $(2.1 \pm 0.01$ $\left.\mu \mathrm{P} \mathrm{L}^{-1}\right)$ treatments than in the "no migration" treatments $\left(1.5 \pm 0.02 \mu \mathrm{g} \mathrm{P} \mathrm{L}^{-1}\right): p=0.036$. When considering only the "no migration" treatments, SRP concentrations in the "small" communities were significantly higher than in the "large" communities $(p=0.018)$.

\section{Phytoplankton abundance}

There was a significant interaction effect of phytoplankton community type and migration behavior on chlorophyll- $a$ concentrations $\left(F_{(1,8)}=7.01, p=0.029\right)$ (Fig. 2b). Again, in the "small" communities post hoc analyses showed no significant effect of migration treatments on
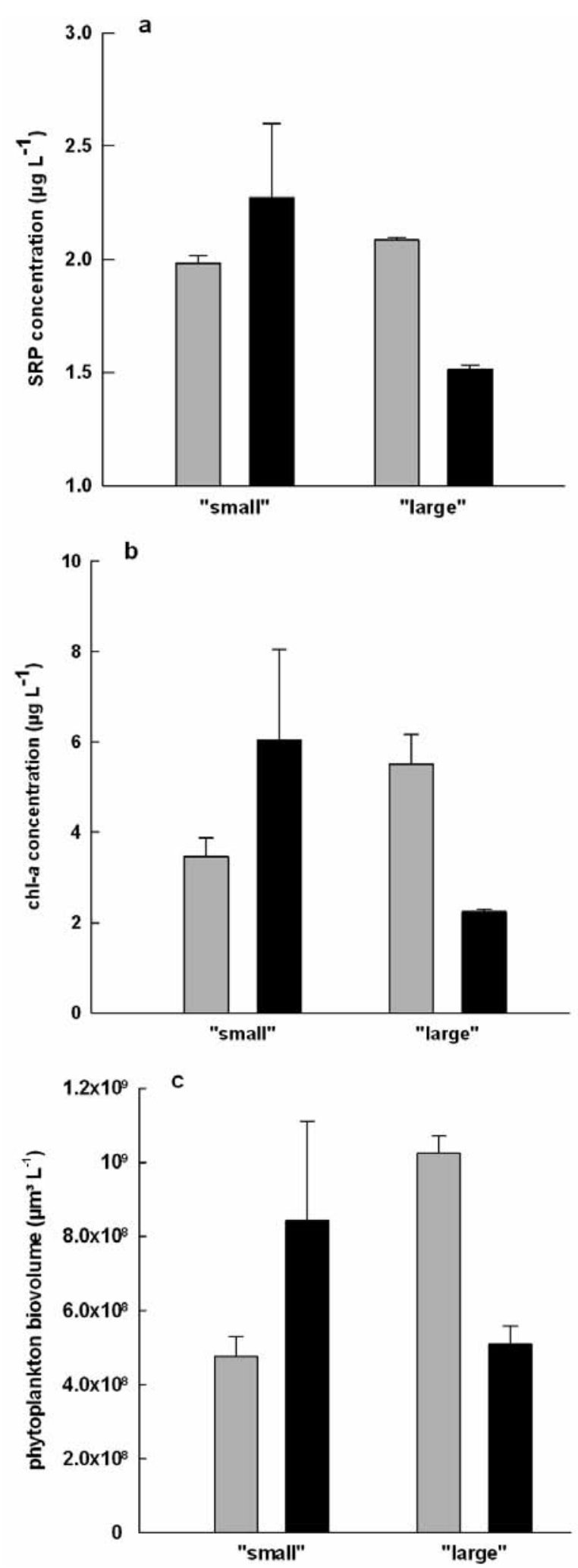

Fig. 2. Mean ( $\pm 1 \mathrm{SE}) \mathrm{SRP}$ (soluble reactive phosphorus) concentrations (a), chlorophyll- $a$ concentrations (b) and total phytoplankton biovolume (c) in Daphnia "migration" (light grey) and Daphnia "no migration" (dark grey) treatments of the "small" and "large" communities. 

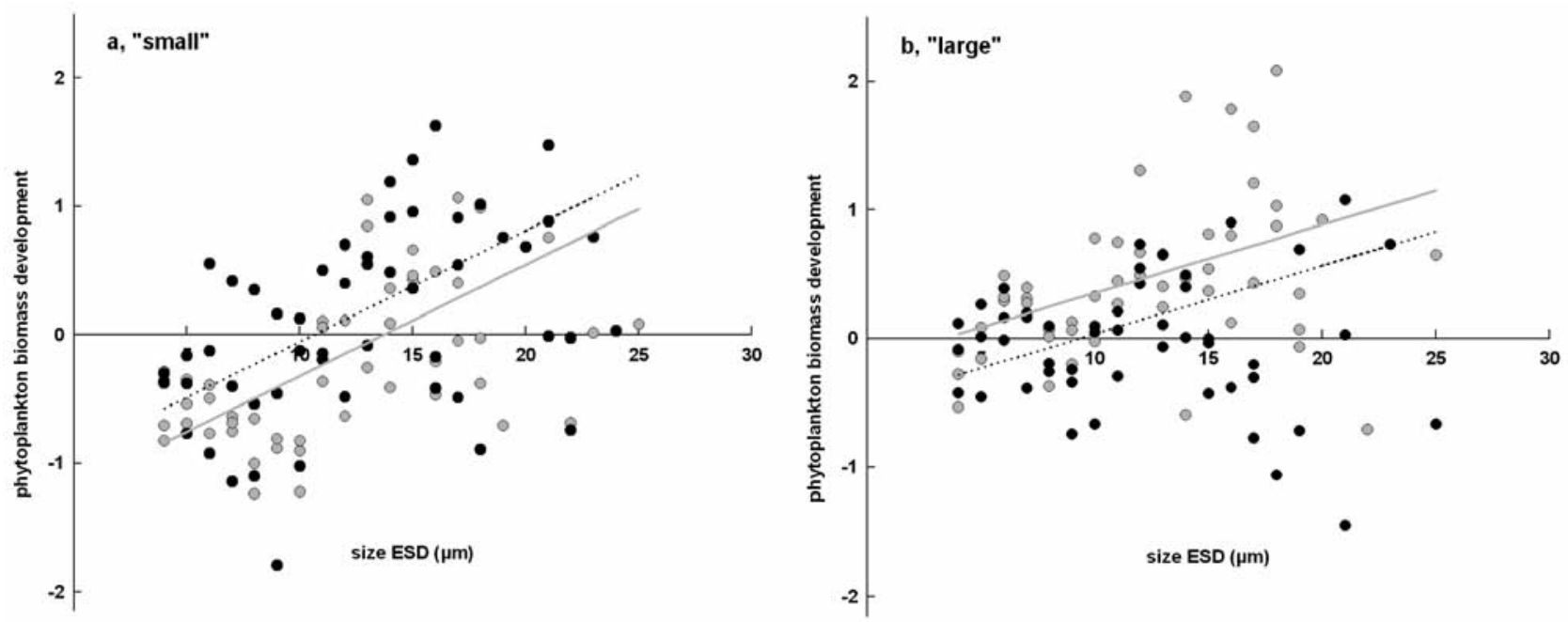

Fig. 3. Phytoplankton biomass size class development in "migration" (gray circles) and "no migration" (black circles) treatments of "small" (a) and "large" (b) communities. Lines represent combined linear regressions. "Small" communities: "migration" treatments, $\mathrm{y}=0.09 \mathrm{x}-1.19 ; R^{2}=0.41$ (gray line); "no migration" treatments, $\mathrm{y}=0.09 \mathrm{x}-0.92 ; R^{2}=0.22$ (dotted line). "Large" communities: "migration" treatments, $\mathrm{y}=0.05 \mathrm{x}-0.18 ; R^{2}=0.27$ (gray line); "no migration" treatments, $\mathrm{y}=0.05 \mathrm{x}-0.50 ; R^{2}=0.07$ (dotted line).

mean chlorophyll- $a$ concentrations: $3.5 \pm 0.4 \mu \mathrm{g}$ chl a L $\mathrm{L}^{-1}$

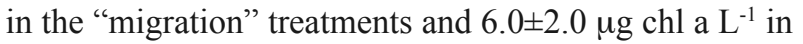
the "no migration" treatments. However, post hoc analyses indicated that in the "large" communities chlorophyll$a$ concentrations of the "migration" treatments $(5.5 \pm 0.7$ $\mu \mathrm{g}$ chl a $\mathrm{L}^{-1}$ ) were significantly higher than in the "no migration" treatments $\left(2.2 \pm 0.1 \mu \mathrm{g} \mathrm{chl} \mathrm{a} \mathrm{L}^{-1}\right): p=0.029$. Also, when considering only the "migration" treatments, chlorophyll- $a$ concentrations of the "large" communities were significantly higher $(p=0.038)$ than in the "small" communities.

As with chlorophyll- $a$, there was a significant interaction effect of phytoplankton community type and migration behavior on total phytoplankton biovolume $\left(F_{(1,8)}=7.55, p=0.025\right)$ (Fig. 2c). Post hoc analyses revealed no significant differences in mean total phytoplankton biovolume between migration treatments in the "small" communities: "migration" treatments $\left(4.6 \times 10^{8} \pm 5.4 \times 10^{7}\right.$ $\left.\mu \mathrm{m}^{3} \mathrm{~L}^{-1}\right)$ and "no migration" treatments $\left(8.4 \times 10^{8} \pm 2.7 \times 10^{8}\right.$ $\left.\mu \mathrm{m}^{3} \mathrm{~L}^{-1}\right)$.

Post hoc analyses showed, that in the "large" communities, biovolume in migration treatments $\left(1.0 \times 10^{9} \pm 4.6 \times 10^{7} \mu \mathrm{m} 3 \mathrm{~L}^{-1}\right)$ was significantly higher than in the "no migration" treatments $\left(5.1 \times 10^{8} \pm 4.8 \times 10^{7} \mu^{3}\right.$ $\left.\mathrm{L}^{-1}\right): p=0.044$. Also, considering only the "migration" treatments, phytoplankton biovolume of the "large" communities was significantly higher $(p=0.030)$ than the "small" communities.

\section{Phytoplankton community size dependent growth rates}

To identify size dependent responses of both phytoplankton communities to the "migration" and "no migra- tion" treatments, we analyzed the biomass development of phytoplankton $(r)$ as a function of size.

Linear regressions of phytoplankton biomass development as a function of size in the "small" communities were significant for both migration treatments: "migration": $\mathrm{y}=0.09 \mathrm{x} 1.24, R^{2}=0.41, F_{1,43}=29.63, \mathrm{p}<0.001$; "no migration": $\mathrm{y}=0.08 \mathrm{x} 0.87, R^{2}=0.22, F_{1,42}=12.16, p=0.001$. Analysis of covariance revealed no statistical differences between slopes $\left(F_{1,85}=0.12, p=0.73\right)$, but there were statistical differences between the intercepts of the regression $\left(F_{1,85}=15.02, \mathrm{p}<0.001\right)$. These results allow a new calculation of linear regressions with a combined mean slope: "migration" treatments, $\mathrm{y}=0.09 \mathrm{x}-1.19, R^{2}=0.41, \mathrm{p}<0.001$; "no migration" treatments, $\mathrm{y}=0.09 \mathrm{x}-0.92, R^{2}=0.22$, $p=0.001$ (Fig. 3a). The results indicate higher biomass development in the "no migration" treatments compared to "migration" treatments of the "small" communities. Additionally, growth rates were positive for phytoplankton species larger than $11 \mu \mathrm{m}$ ESD for "no migration" treatments, whereas this was only the case for size classes larger than $14 \mu \mathrm{m}$ ESD in the migration treatments.

Linear regressions of phytoplankton biomass development as a function of size in the "large" communities were only significant for "migration" treatments: $\mathrm{y}=0.07 \mathrm{x}-0.33, R^{2}=0.27, F_{1,46}=17.32, \mathrm{p}<0.001$. "No migration" treatments showed no significant relation-ship between biomass development and size: $\mathrm{y}=0.03 \times 0.23$, $R^{2}=0.07, F_{1,36}=2.53, p=0.12$. Analysis of covariance revealed no statistical differences in the slopes $\left(F_{1,82}=2.70\right.$, $p=0.10$ ), but there were statistical differences in the intercepts $\left(F_{1,83}=9.88, p=0.002\right)$ between regressions. These results allow a new calculation of linear regressions with a 
combined mean slope: "migration" treatments, $\mathrm{y}=0.05 \mathrm{x}$ $0.18, R^{2}=0.27$; "no migration" treatments, $\mathrm{y}=0.05 \mathrm{x}-0.50$, $R^{2}=0.07$ (Fig. 3b). The results indicate higher biomass development in the "migration" treatments compared to "no migration" treatments of the "large" communities. Additionally, biomass development was positive for all phytoplankton size classes in "migration" treatments. "No migration" treatments had no clear effect on size dependent bio-mass development in the "large" communities.

\section{DISCUSSION}

We experimentally manipulated the size distribution of a natural summer phytoplankton community in a small oligotrophic lake. We exposed the resulting communities to migrating and non-migrating zooplankton populations. In general, both phytoplankton communities responded with the higher growth of larger algae when exposed to grazing by Daphnia, which was indicated by the positive relationship between biomass development and algal size. This general response was similar between "migration" and "no migration" treatments, as shown by the similar slopes of the size-bio-mass development relationships. Nevertheless, zoo-plankton DVM had a different effect on phytoplankton growth, which was dependent on phytoplankton size structure.

We could observe a loss in total phytoplankton biovolume during our experiments caused by grazing; however, the grazing losses were to some extent counterbalanced by DVM related effects. Those effects were different between "small" and "large" communities, which can be seen on the different total phytoplankton biovolume patterns. Our hypothesis that different phytoplankton size distributions could affect the direction and strength of the community response to zooplankton DVM is therefore supported by the results. We were able to show experimentally, that the effects of zooplankton DVM on phytoplankton may be modified by phytoplankton size structure manipulations. However, our general expectations were mainly met by the results from treatments with the "large" communities.

The "large" communities followed the general predictions (stated in the introduction) that zooplankton DVM would cause higher phytoplankton abundance by promoting algae that are able to use the temporal refuge from grazing for growth. However, it seems that a full phytoplankton community size spectrum was necessary for zooplankton DVM to induce a refuge effect for algae. Phytoplankton only profited from zooplankton DVM in treatments containing large algae. However, contrary to the expectations stated in the introduction that mainly small algae should profit, larger algae also profited from "migration" treatments in the "large" communities. The results obtained from the "small" communities, which were mainly absent of large algae, suggest impacts to the contrary. For example, continuous grazing instead of discontinuous grazing resulted in higher phytoplankton biomass.

The results of the "small" treatments fit well to an earlier mesocosm study in the same lake, in which a non-manipulated phytoplankton community was exposed to zooplankton DVM (Haupt et al. 2009). In the above mentioned study, permanent grazing resulted in higher phytoplankton abundance by fostering small phytoplankton species with gelatinous sheaths. Theoretical concepts and empirical studies suggest that under oligotrophic conditions, the benefits of grazing mediated by nutrient recycling may balance or even overyield mortality related grazing losses (Sterner 1990; Elser, and Urabe 1999; Nugraha et al. 2010). Other possible explanations could be based on the interactions between microzooplankton, such as ciliates, and Daphnia (Juergens 1994). Phytoplankton communities consisting of mainly small algae suffering from serious predation by ciliates could benefit from the continuous presence of Daphnia, which are known to be able to drastically reduce microzooplankton biomass (Zoellner et al. 2003). Hence, more detailed studies are necessary to disentangle the different possibilities of how small, ingestible algae in natural lake communities are able to still profit from permanent grazing.

Since all other variables were controlled in the experiment, the observed differences in phytoplankton response to zooplankton DVM were directly associated with the manipulation of phytoplankton size structure. The phosphorus data also suggest that nutrient recycling by Daphnia appeared to be crucial for phytoplankton development in "small" treatments containing high proportions of small, algae. In the "small" treatments with continuous grazing, sustained removal of edible algae resulted in noticeably more dynamic nutrient recycling with higher phosphorus availability. Boersma, and Wiltshire (2006) showed that Daphnia excrete up to about $80 \%$ phosphorus as soluble reactive phosphorus (SRP), which means that higher nutrient recycling by grazing should be coupled with a higher release of SRP. This hypothesis is supported in our study, whereby significantly higher SRP concentrations in the "small" community "no migration" treatments compared to the "migration" treatments with discontinuous zooplankton grazing.

Obviously, the response of phytoplankton communities to zooplankton DVM was dependent on the presence or absence of large algae. The phytoplankton data, together with the nutrient measurements, indicate that the refuge effects of zooplankton DVM were stronger in "large" communities compared to the effects of nutrient recycling. Large algae have the potential to store nutrients more effectively, and remove larger parts of the dissolved phosphorus pool (Wen et al. 1997). Furthermore, their lower edibility would also lead to lower recycling of phos- 
phorus in communities with a higher proportion of large algae. In direct contrast, small algae with lower storage abilities for phosphorus and higher edibility would foster higher nutrient turnover and recycling. Therefore, in communities mainly consisting of small algae the effect of nutrient recycling (which would be even higher in "no migration" treatments with constant grazing) may be more important than the refuge effects of zooplankton DVM. The observed size dependent interactions of zooplankton DVM with phytoplankton community structure support that both the refuge effects and size structure depend on nutrient recycling as the main drivers of how zooplankton DVM affects phytoplankton abundance.

The question arises in which kind of environment small or large algae are favored and influenced by zooplankton DVM. One important parameter determining the size of phytoplankton is nutrient availability (Sommer 2000): low nutrient levels promote small size classes of algae, whereas high nutrient levels result in the opposite. DVM in oligotrophic systems may therefore result in phytoplankton responses similar to our "small" treatments, while eutrophic systems are more likely to show responses towards DVM as our "large" treatments.

\section{CONCLUSIONS}

Diel vertical migration of zooplankton is a classic example of a so called trait mediated effect. Trait mediated effects describe trophic cascades that are not mediated by direct mortality but by the behavioral responses of herbivores through predators (Schmitz et al. 2004). Our experimental results suggest that the direction and strength of trait mediated effects may depend on the distribution of functional traits within a community. If functional traits, such as body size, determine the flow of energy and matter within trophic cascades, the distribution of these functional traits should also influence the strength and the direction of cascade flows. In our experimental system, algal cell size not only influenced direct mortality by grazers, but also the supply of dissolved nutrients available for total phytoplankton growth. Substantial dominance by small algae resulted in trait mediated trophic cascades that were different in strength and direction from that observed for the community in which size classes were more evenly distributed, and where large species were more common. Whether the indirect trophic cascade mediated by zooplankton DVM resulted in a positive or negative effect on the trophic level of primary producers, it was clearly a function of the size distribution of the phytoplankton.

Since trait mediated trophic cascades appear to depend on functional trait distributions within primary producer communities, significant alterations in environmental factors could severely affect conditions within lake ecosystems. Global warming may be one such factor. For example, increasing spring air temperatures could result in earlier stratification and spring algae blooms (Winder et al. 2004; Berger et al. 2010). In contrast, zooplankton dynamics are primarily governed by water temperature (Bottrell 1975; Reichwaldt et al. 2004) and only to a lesser extent by earlier stratification. Accelerated stratification processes caused by global warming may lead to an earlier "clear water" phase, which would lead to earlier phytoplankton community succession (Berger et al. 2010) from smaller fast growing spring species to larger and slower growing summer phytoplankton species. Therefore a significant grazing on bloom forming algae occurs only after a lag phase caused by zooplankton population development. That could result in a mismatch between phytoplankton and zooplankton cycles. If zooplankton misses the opportunity to capitalize on a highly edible spring bloom of small algal species, they may be forced to rely on less edible post-bloom phytoplankton communities. This negative impact on zooplankton growth could cascade to young fish, which consume zooplankton as a significant part of their diet. Therefore, the complex interaction between phytoplankton size structure, fish predation, and zooplankton DVM may adjust in response to increasing warming.

\section{ACKNOWLEDGMENTS}

This study was supported by a grant from the German Research Foundation (DFG STI 180/3). We thank A. Wild, A. Weigert and M. Schlössler for technical support during the field experiment.

\section{REFERENCES}

Attayde JL, and Hansson LA. 1999. Effects of nutrient recycling by zooplankton and fish on phytoplankton communities. Oecologia 121: 47-54.

Berger SA, Diehl S, Stibor H, Trommer G, and Ruhenstroth M. 2010. Water temperature and stratification depth independently shift cardinal events during plankton spring succession. Global Change Biol. 16: 1954-1965.

Boersma M, and Wiltshire KH. 2006. Gut passage of phosphorus-limited algae through Daphnia: do they take up nutrients in the process? Arch. Hydrobiol. 167: 489-500.

Bottrell HH. 1975. Relationship between temperature and duration of egg development in some epiphytic cladocera and copepoda from River Thames, Reading, with a discussion of temperature functions. Oecologia 18: 63-84.

Cohen JE, Pimm SL, Yodzis P, and Saldana J. 1993. Body sizes of animal predators and animal prey in food webs. J. Anim. Ecol. 62: 67-78.

Diehl S, Berger S, Ptacnik R, and Wild A. 2002. Phytoplankton, light, and nutrients in a gradient of mixing depths: Field experiments. Ecology 83: 399-411.

Elser JJ, and Urabe J. 1999. The stoichiometry of consumer-driven nutrient recycling: Theory, observations, and consequences. Ecology 80: 735-751.

Gaston KJ, and Lawton JH. 1988. Patterns in body size, population dynamics, and regional distribution of bracken herbi- 
vores. Am. Nat. 132: 662-680.

Haney JF, and Hall DJ. 1973. Sugar coated Daphnia: a preservation technique for Cladocera. Limnol. Oceanogr. 18: 331 333.

Haupt F, Stockenreiter M, Baumgartner M, Boersma M, and Stibor H. 2009. Daphnia diel vertical migration: implications beyond zooplankton. J. Plankt. Res. 31: 515-524.

Haupt F, Stockenreiter M, Reichwaldt ES, Baumgartner M, Lampert W, Boersma M, and Stibor H. 2010. Upward phosphorus transport by Daphnia diel vertical migration. Limnol. Oceanogr. 55: 529-534.

Hays GC. 2003. A review of the adaptive significance and ecosystem consequences of zooplankton diel vertical migrations. Hydrobiologia 503: 163-170.

Huber AMR, Peters F, and Lorke A. 2011. Active and passive vertical motion of zooplankton in a lake. Limnol. Oceanogr. 56: 695-706.

Juergens K. 1994. Impact of Daphnia on planktonic microbial food webs: A review. Marine Microbial Food Webs 8: 295324.

Lampert,W. 1987. Vertical migration of freshwater zoo-plankton: Indirect effects of vertebrate predators on algal communities. In: Kerfoot, W.C., and A. Sih (Eds), Predation: direct and indirect impacts on aquatic communities. 1. University press of England. New Hampshire: 291-298.

Lampert W. 1989. The adaptive significance of diel vertical migration of zooplankton. Funct. Ecol. 3: 21-27.

Lampert W, Fleckner W, Rai H, and Taylor BE. 1986. Phytoplankton control by grazing zooplankton - a study on the spring clear-water phase. Limnol. Oceanogr. 31: 478-490.

Lampert W, Schmitt RD, and Muck P. 1988. Vertical migration of fresh-water zooplankton - test of some hypotheses predicting a metabolic advantage. B. Mar. Sci. 43, 620-640.

Lampert W, and Grey J. 2003. Exploitation of a deep-water algal maximum by Daphnia: a stable-isotope tracer study. Hydrobiologia 500: 95-101.

Loose CJ, and Dawidowicz P. 1994. Trade-offs in diel vertical migration by zooplankton - The costs of predator avoidance. Ecology 75: 2255-2263.

Loose CJ, Von Elert E, and Dawidowicz P. 1993. Chemicallyinduced diel vertical migration in Daphnia - a new bioassay for Kairomones exuded by fish. Arch. Hydrobiol. 126: 329337.

Nugraha A, Pondaven P, and Treguer P. 2010. Influence of consumer-driven nutrient recycling on primary production and the distribution of $\mathrm{N}$ and $\mathrm{P}$ in the ocean. Biogeosciences 7: 1285-1305.

Petzoldt T, Rudolf L, Rinke K, and Benndorf J. 2009. Effects of zooplankton diel vertical migration on a phytoplankton community: A scenario analysis of the underlying mechanisms. Ecol. Model. 220: 1358-1368.

Reichwaldt ES, and Stibor H. 2005. The impact of diel vertical migration of Daphnia on phytoplankton dynamics. Oecologia 146: 50-56.

Reichwaldt ES, Wolf ID, and Stibor H. 2004. The effect of dif- ferent zooplankton grazing patterns resulting from diel vertical migration on phytoplankton growth and composition: a laboratory experiment. Oecologia 141: 411-419.

Reichwaldt ES, Wolf ID and Stibor H. 2005. Effects of a fluctuating temperature regime experienced by Daphnia during diel vertical migration on Daphnia life history parameters. Hydrobiologia 543, 199-205.

Reynolds CS, and Irish AE. 1997. Modelling phytoplankton dynamics in lakes and reservoirs: the problem of in-situ growth rates. Hydrobiologia 349: 5-17.

Ringelberg J. 1991. A mechanism of predator-mediated induction of diel vertical migration of Daphnia hyalina. J. Plankt. Res. 13: 83-89.

Schindler DE. 1992. Nutrient regeneration by Sockeye-salmon (Oncorhynchus nerka) fry and subsequent effects on zooplankton and phytoplankton. Can. J. Fish. Aquat. Sci. 49: 2498-2506.

Schmitz OJ, Krivan V, and Ovadia O. 2004. Trophic cascades: the primacy of trait-mediated indirect interactions. Ecol. Lett. 7: 153-163.

Sokal RR, and Rohlf FJ. 1981 Biometry. W. H. Freeman and Company, New York

Sommer U, Gliwicz ZM, Lampert W, and Duncan A. 1986. The PEG-model of seasonal succession of planktonic events in fresh waters. Arch. Hydrobiol. 106: 433-471.

Sommer U. 2000. Scarcity of medium-sized phytoplankton in the northern Red Sea explained by strong bottom-up and weak top-down control. Mar. Ecol. Prog. Ser. 197: 19-25.

Sterner RW. 1990. The ratio of nitrogen to phosphorus resupplied by herbivores - zooplankton and the algal competitive arena. Am. Nat. 136: 209-229.

Stich HB, and Lampert W. 1984. Growth and reproduction of migrating and non-migrating Daphnia species under simulated food and temperature conditions of diurnal vertical migration. Oecologia 61: 192-196.

Vanni MJ, and Layne CD. 1997. Nutrient recycling and herbivory as mechanisms in the "top-down" effect of fish on algae in lakes. Ecology 78: 21-40.

Wen YH, Vezina A, and Peters RH. 1997. Allometric scaling of compartmental fluxes of phosphorus in freshwater algae. Limnol. Oceanogr. 42: 45-56.

Wetzel RG, and Likens GE. 1991. Limnological analyses. Springer. New York.

Williams RJ, and Martinez ND. 2000. Simple rules yield complex food webs. Nature 404: 180-183.

Winder M, and Schindler DE. 2004. Climatic effects on the phenology of lake processes. Global Change Biol. 10: 18441856.

Zaret TM, and Suffern JS. 1976. Vertical migration in zooplankton as a predator avoidance mechanism. Limnol. Oceanogr. 21: 804-813.

Zoellner E, Santer B, Boersma M, Hoppe HG, and Juergens K. 2003. Cascading predation effects of Daphnia and copepods on microbial food web components. Freshwater Biol. 48: 2174-2193. 